PROGRESS REPORT

DE82 005513

THE UNITED STATES DEPARTMENT OF ENERGY

CONTRACT NO. DE-ACO2-76EV03522-A004

BIOLOGICAL AND CLINICAL DOSIMETRY

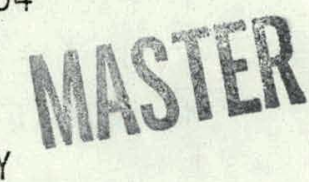

Contract Period: January 1, 1981 - December 31, 1981

Report Period: October 1, 1980 - September 30, 1981

Principal Investigator: John S. Laughlin, Ph.D., Member

Co-Principal Investigator: Louis Zeitz, Ph.D., Associate Member

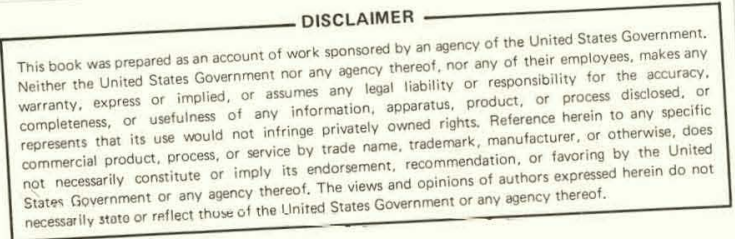

Sloan-Kettering Institute for Cancer Research

Radiation Biophysics Laboratory

410 East 68th Street

New York, N.Y. 10021

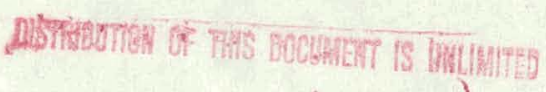

MGe

September 30, 1981

there is no objection from the paten point of view to the perbication or disservination of the documen(s) folsed in this loster.

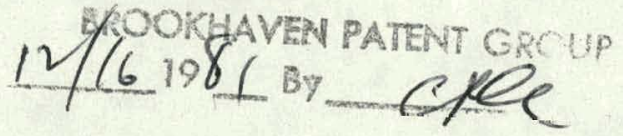




\section{DISCLAIMER}

This report was prepared as an account of work sponsored by an agency of the United States Government. Neither the United States Government nor any agency Thereof, nor any of their employees, makes any warranty, express or implied, or assumes any legal liability or responsibility for the accuracy, completeness, or usefulness of any information, apparatus, product, or process disclosed, or represents that its use would not infringe privately owned rights. Reference herein to any specific commercial product, process, or service by trade name, trademark, manufacturer, or otherwise does not necessarily constitute or imply its endorsement, recommendation, or favoring by the United States Government or any agency thereof. The views and opinions of authors expressed herein do not necessarily state or reflect those of the United States Government or any agency thereof. 


\section{DISCLAIMER}

Portions of this document may be illegible in electronic image products. Images are produced from the best available original document. 


\title{
BIOLOGICAL AND CLINICAL DOSIMETRY \\ PROGRESS REPORT
}

For Period October 1, 1979 - September 30, 1980

John S. Laughlin

and

Louis Zeitz

\begin{abstract}
Sloan-Kettering Institute for Cancer Research
410 East 68th Street
\end{abstract}

New York, New York 10021

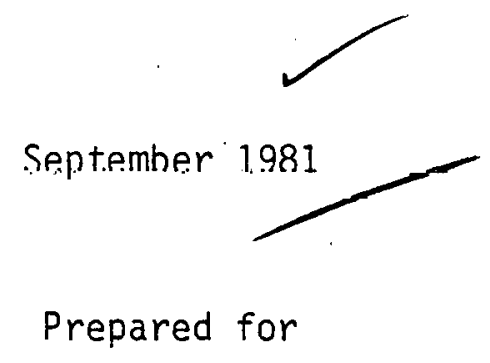

The United States Department of Energy

Under Contract No. DE-ACO2-76EV03522-A004 
This report was prepared as an account of work sponsored by the United States Government. Neither the United States nor the United States Department of Energy, nor any of their employees, makes any warranty, express or implied, or assumes any legal lability or responsibility for the accuracy, completeness, or unsefulness of any information, apparatus, product or process disclosed or represents that its use would not infringe privately owned rights. 


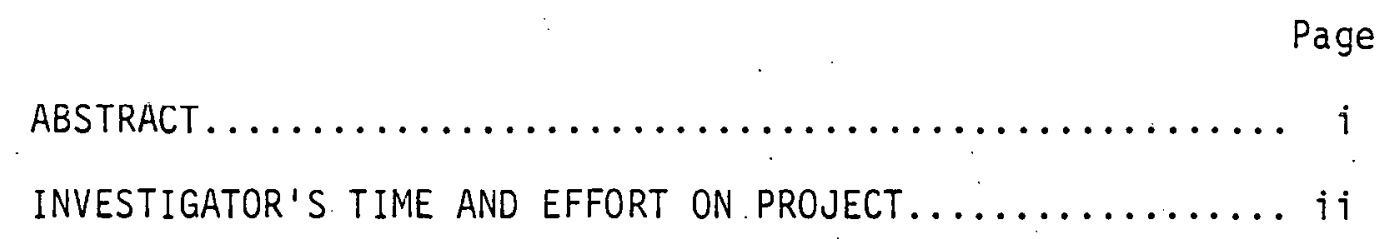

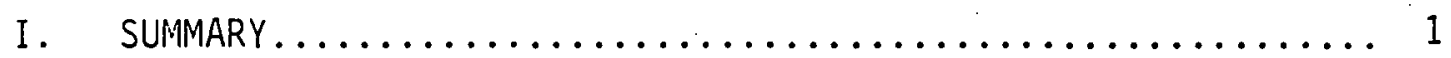

II. MICRODOSIMETRY............................ 2

III. "NON-ISOLATED-SENSOR" Solid Polystyrene Calorimeter...... 6 REFERENCES............................... 8 PUBLICATIONS AND PRESENTATIONS.................... 9 
BIOLOGICAL AND CLINICAL DOSIMETRY

\section{ABSTRACT}

A second measurement of the event size distribution for $20 \mathrm{MeV}$ neutrons was carried out at Ohio University to determine the reproducability of results. Again a significant difference between measurement and theoretical calculations by Caswell and Coyne was found. The measured fraction of events due to alpha particles was significantly lower than that predicted by the calculation of Caswell and Coyne. Furthermore, the discrepancies with the theoretical calculations made by Caswell and Coyne were confirmed by measurements made with a differently designed $T-E$ proportional counter.

A "non-isolated-sensor" solid polystyrene calorimeter was constructed and tested during the past year. It has the advantages of 1) simple construction 2) simple operation, without vacuum or feedback for temperature control 3) the capability of obtaining simultaneous measurements at different depths and azimuthal angle and 4 ) the possibility of obtaining measurements with the calorimeter directed in any orientation. 


\section{BIOLOGICAL AND CLINICAL DOSIMETRY}

\section{INVESTIGATORS TIME \& EFFORT ON PROJECT}

The principal investigator has devoted approximately $15 \%$ of his time and the co-principal investigator approximately $50 \%$ of his time to the projects described herein. These percentages are not expected to change during the remainder of the current term. 


\section{SUMMARY}

In the last year we have been able to verify the event size distribution previously measured for a nearly monoenergetic $20 \mathrm{MeV}$ neutron beam. The event size distribution obtained with an A-150 plastic walled. counter (EG\&G Model LET-1/2) gas filled to give an effective diameter of I $\mathrm{m}$ was similar in shape to that obtained with a Rossi type spherical, wall-less chamber with effective diameter of $0.3 \mu \mathrm{m}$. With both counters, the measured fraction of events due to alpha particles was significantly lower than that predicted by the calculatins of Caswell and Coyne.

A "non-isolated-sensor" solid polystyrene calorimeter was constructed and evaluated. The advantages of this type of calorimeter are: 1) simplicity of construction, 2) simplicity of operation without vacuum or feedback for temperature control, 3) capability of simultaneous measurements at several depths and azimuthal angles, 4) operation with the calorimeter in any orientation, and 5) very low thermal defect corretion with polystyrene. 


\section{MICRODOSIMETRY}

\section{Introduction}

Measurements of event-size distribution in 1 ineal energy were repeated in nearly monoenergetic neutron beams whose principal energies were 20 and $25 \mathrm{MeV}$. The main objective in carrying out this work was to see if the previous results were reproducible. The earlier measurements for $20 \mathrm{MeV}$ neutrons demonstrated significant discrepancies with the theoretical calculatins by Caswell and Coyne (1-3), Fig (1). Additional measurements were made by J. Dicello of Los Alamos Scientific Laboratory using a counter of a different design to see if results would be comparable. A tissue equivalent ionization chamber and a G-M counter were also used in the neutron beams to obtain dose rate and gamma component information.

\section{Description of experiment}

The 20 and $25-\mathrm{MeV}$ neutrons in this study were produced with the $T(d, n)$ reaction using a pulsed deuteron beam from the Ohio University tandem accelerator with respective deuteron energies of 3.9 and $8.11 \mathrm{MeV}$. The neutron energy spectra were measured by time-of-flight technique (4).

Our proportional counter was a commercially produced (EG\&G Model LET-1/2) A-150 plastic walled instrument. It was filled with propanebased tissue equivalent gas to a pressure of 33 torr thereby simulating an effective counter diameter of $1 \mu \mathrm{m}$. A-150 build-up cap of appropriate thickness was used to insure charged particle equilibrium. The other counter used was a Rossi type spherical, wall-less chamber with effective diameter of $0.3 \mu \mathrm{m}$. The tissue equivalent ionization chamber was a $1.0 \mathrm{c} . \mathrm{c}$. spherical chamber produced commercially (Far West Technology IC-17). This chamber was employed to measure the total absorbed dose in A-150. The gamma component in the neutron beam was measured by a G-M counter designed and assembled at Sloan-Kettering Institute (5).

The counting system consists of three amplifiers with different gains operated in pareallel to observe the entire event-size distribution in one measurement. The data was stored by a mini-computer in three normal linear arrays. Each event was weighted by its pulse height and logarithmically re-binned to obtain the $y^{2} d(y)$ versus $\log (y)$ spectrum in real time. This unique system enabled on-the-spot viewing of these spectra as the measurement proceeded. The data for $20 \mathrm{MeV}$ run was converted from Ohio University's data disk integer format to a card image format and stored on tape so that the results could be processed by the S.K.I. PDP $11 / 70$ computer using an established program (6). 


\section{Results}

The event size distribution for $20-\mathrm{MeV}$ neutrons in a $1.0 \mathrm{\mu m}$ simulated cavity obtained is shown in Fig. (2). It demonstrated a very similar form to that obtained previously. The main features of the spectrum are recapitulated and thus confirming the deviations from the theoretical calculation. Again, the measured spectrum revealed more details in the region between 100 and $500 \mathrm{keV} \cdot \mu \mathrm{m}^{-1}$. The proton and alpha edges are both resolved in this region. The number of events de to alpha particles in this region is significantly less than that calculated.

The 20-MeV spectrum measured by Dicel10's $0.3 \mu \mathrm{m}$ wall-less counter displayed a similar shape compared to ours but with slightly more resolution in the proton and alpha edge region. Due to the time limitation, this data was not translated into the format suitable for analysis by our computer system but it was felt that large discrepancies would not be observed.

Techniques were not well established to obtain the event-size distribution in the $25-\mathrm{MeV}$ beam. The major difficulty encountered was the low energy neutron contaminants from the beam which was produced from the interaction of incident charged particles with target backing materials.

Ionization chamber and G-M counter measurements in both 20 and $25-\mathrm{MeV}$ neutron beam are summarized in Table (1). 


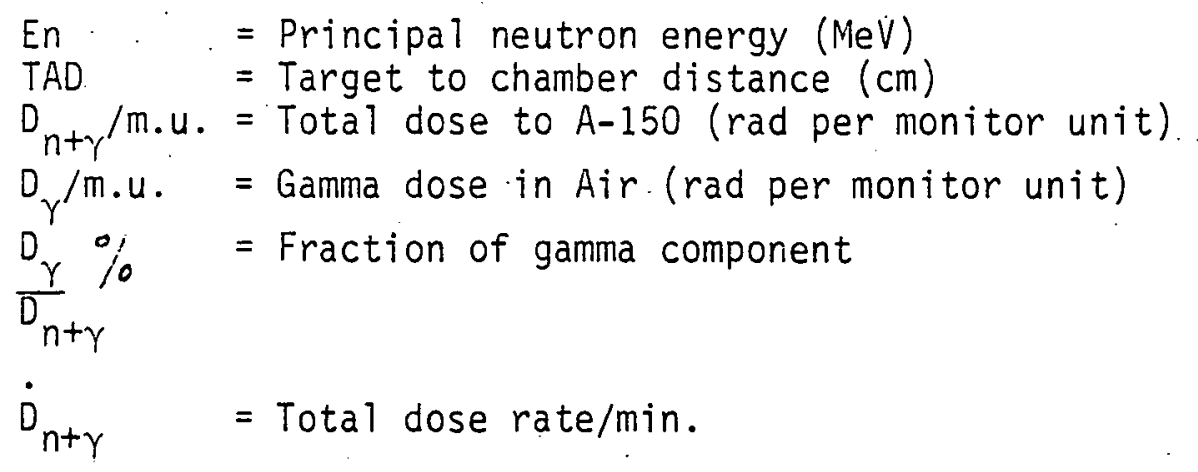

IONIZATION CHAMBER MEASUREMENT IN AIR

TABLE (1)

\begin{tabular}{|c|c|c|c|c|c|}
\hline $\begin{array}{c}\mathrm{En} \\
(\mathrm{MeV}) \\
\end{array}$ & $\begin{array}{l}\text { TAD } \\
(\mathrm{Cm}) \\
\end{array}$ & $\begin{array}{c}\frac{D_{n+\gamma}}{m \cdot u \cdot} \\
\left(\times 10^{-6} \frac{r a d}{m \cdot u}\right)\end{array}$ & $\begin{array}{c}\frac{D_{\gamma}}{\mathrm{m} \cdot \mathrm{u} .} \\
\left(\times 10^{-6} \frac{\mathrm{rad}}{\mathrm{m} \cdot \mathrm{u}}\right)\end{array}$ & $\frac{D_{\gamma}}{D_{n+\gamma}}$ & $\begin{array}{l}D_{n+\gamma} \\
\frac{(r a d)}{\min }\end{array}$ \\
\hline 20 & 15.0 & 9.36 & 0.512 & 5.47 & 0.076 \\
\hline 20 & 30.0 & 1.62 & 0.122 & 7.50 & 0.013 \\
\hline 25 & 15.0 & 21.87 & 0.725 & 3.31 & 0.509 \\
\hline 25 & 30.0 & 7.30 & 0.334 & 4.58 & 0.180 \\
\hline
\end{tabular}

The gamma-ray background was in close agreement with that recorded by the time-of-flight system. 


\section{Conclusions}

Event-size distribution measurements in $20 \mathrm{MeV}$ monoenergetic neutron beam using $T-E$ proportional counters have demonstrated consistent results with measurements made the previous year. Furthermore, the discrepancies with the theoretical calculations made by Caswell and Coyne were confirmed by the measurements made using a T-E proportional counter designed and made differently. To summarize, the most obvious differences in the measured distribution were more details in the 100 to $500-\mathrm{KeV}_{\text {. um-1 }}$ region with distinct proton and alpha edges as well as fewer events due to alpha particles.

It is reasonable, however, to state that the approximate agreement between measurements and calculations is good. At this point no source has been found to generate pure monoenergetic neutrons. However, one must keep in mind that the calculations of event size spectra were based on monoenergetic neutrons. In addition, the nuclear data necessary for computation of events due to alpha particles produced by $20-M e V$ neutrons included that $12 C\left(n, n^{\prime}\right) 3 d$ cross section are not well known at this energy. A small error in the cross section might produce a sizable effect in the calculated event-size spectrum. It is possible that data now being generated at Ohio University and Lawrence Livermore Laboratory will provide more accurate input data for these calculations. 


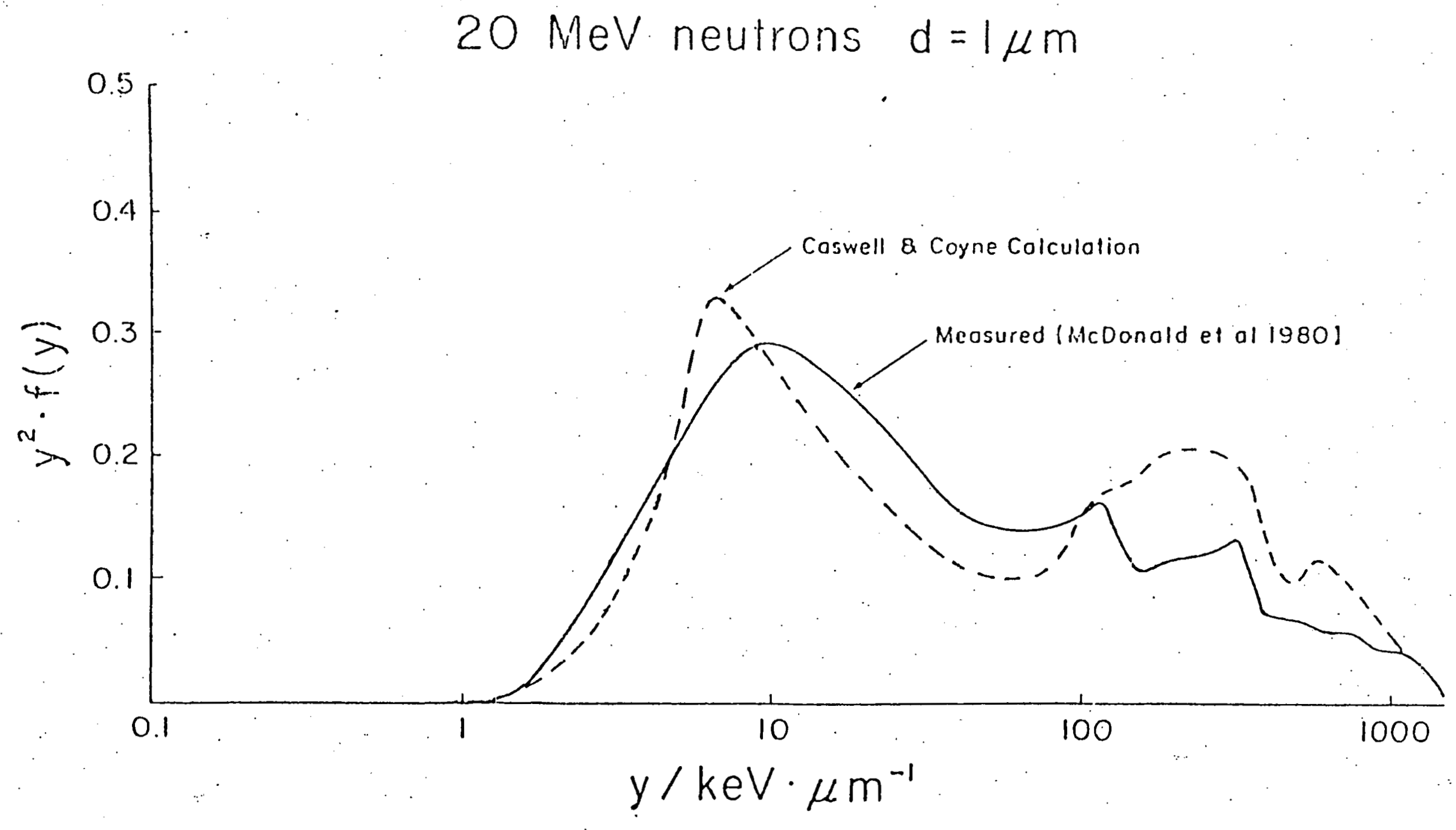




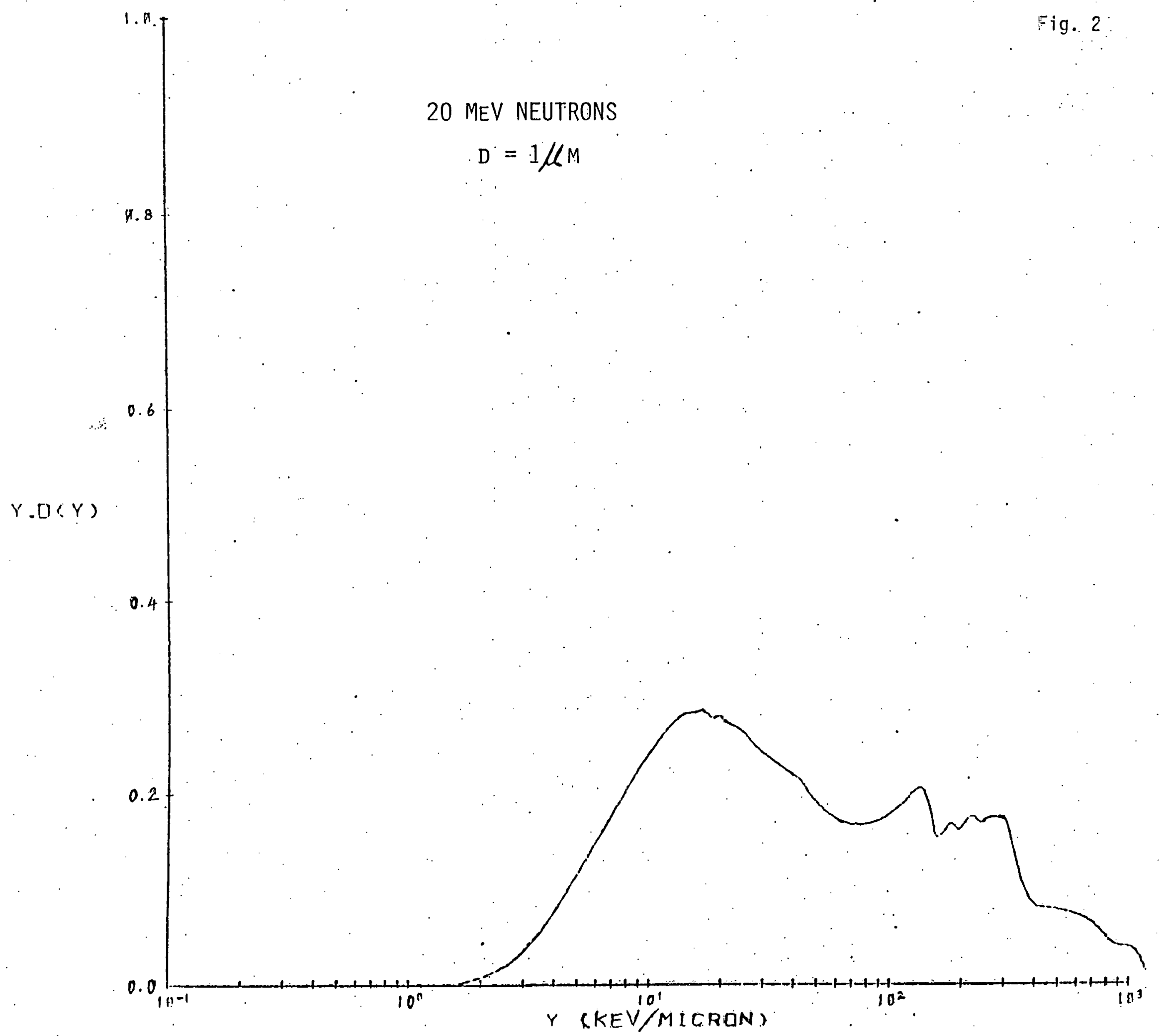




\section{III. "NON-ISOLATED-SENSOR" SOLID POLYSTYRENE CALORIMETER}

A "non-isolated-sensor" solid polystyrene calorimeter was constructed to test the role of thermal diffusion in limiting the length of irradiation time during which temperature measurements with non-isolated sensors could be made sufficiently free of drift for determination of absorbed dose with radiation fields such as gamma, X-rays, and high energy elections (7).

The essential features of the polystyrene calorimeter are shown in Fig. 3. A picture of the calorimeter with its associated bridges, electrometers and dual-pen recorder is shown in Fig. 4.

Assuming neglible heat loss during the period of irradiation, it can be shown that the dose in red absorbed in the polystyrene (PS), D, is:

$$
D=10^{5}\left(\frac{C p}{\alpha}\right)\left(\frac{\Delta R}{R}\right) \times \text { Thermal Defect of PS, where } C P \text { is the specific }
$$

heat in $j g^{-1} k^{-1}$ of PS at temperature $T, \alpha$ is the thermal coefficient of resistance $\alpha=\frac{1}{R} \frac{\Delta R}{\Delta T}$ at $T$, and $(\Delta R / R)$ is the fractional change of resistance due to the increase in temperature caused by the energy absorbed from the radiation field. A value of 1.007 for the thermal defect, based on a report by Sabel et al. (8), was used in calculations of dose. The thermal coefficient of resistance for the thermistors was measured and $C p$ for random samples taken from the PS material used to build this calorimeter were determined by Dr. R.E. Taylor of the Properties Res. Lab., Purdue Univ. (9). Fig. 5.

A typical scan taken with this calorimeter in a co-60 field is shown in

Together, Figs 6 and 7 show that for this geometry the thermal diffusion is sufficiently small in PS for measurements to be made with irradiation times of less than 20 minutes.

Comparisons made of absorbed dose determined by cavity ionization measurements with a PS ionization chamber in a PS phantom at the two depths 0.5 and $5 \mathrm{~cm}$ and with this polystyrene calorimeter are summarized in Table I. The temperatures of the thermistors at the time of measurement were estimated on the basis of room temperature. It can be shown that the error in determining absorbed dose introduced by this method of estimating thermistor temperature should not be greater than $\pm 2 \%$.

The features of this "non-isolated-sensor" solid polystyrene calorimeter that make it worthwhile to investigate further are:

1) Simple construction, 2) simple operation without vacuum or feedback for temperature control, 3) capability of simultaneous measurements at several depths and azimuthal angles, 4) operation with calorimeter in any orientation, and 5) very smal1 correction for thermal defect with PS. 


\section{TABLE I}

COMPARISON OF CALORIMETER AND PANCAKE ION CHAMBER - DOSE TO PS IN RAD/MIN.

\begin{tabular}{|c|c|c|c|c|c|c|}
\hline & Depth & Calorimeter & $\begin{array}{l}\text { Pancake } \\
\text { Chamber } \\
\end{array}$ & $\frac{\text { Calorimeter }}{\text { Pancake Chamber }}$ & $\begin{array}{r}\text { Ratio } \\
\text { Calorimeter } \\
\end{array}$ & $\begin{array}{l}5.0 \mathrm{~cm} \\
0.5 \mathrm{~cm} \\
\text { Pancake Chamber }\end{array}$ \\
\hline $\begin{array}{l}\text { Co- } 60 \\
\text { S.S.D. }-30 \mathrm{~cm} \text { to top } \\
\text { of PS } \\
\text { F.S. }-3 \times 8 \mathrm{~cm}\end{array}$ & $\begin{array}{l}0.5 \mathrm{~cm} \\
5.0 \mathrm{~cm}\end{array}$ & $\begin{array}{l}85.7 \pm 5.5 \% * \\
64.8 \pm 2.0 \% \star\end{array}$ & $\begin{array}{l}87.5 \pm 2.5 \% * \star \\
67.5 \pm 2.5 \% \text { }\end{array}$ & $\begin{array}{l}0.98 \\
0.96\end{array}$ & $0.75 \pm 5.2 \% *$ & $0.77 \pm 3.5 \% \star \star$ \\
\hline $\begin{array}{l}13 \mathrm{MeV} \text { Electrons } \\
\text { S.S.D. }-103.1 \mathrm{~cm} \text { to } \\
\text { top of PS } \\
\text { F.S. }-10 \times 10 \mathrm{~cm}\end{array}$ & $\begin{array}{l}0.5 \mathrm{~cm} \\
5.0 \mathrm{~cm}\end{array}$ & $\begin{array}{l}161.6 \pm 7.4 \% \\
80.71 \pm 3.1 \% *\end{array}$ & $\begin{array}{c}165.7 \pm 2.5 \% \star \star \\
88.7 \pm 2.5 \% \star \star\end{array}$ & $\begin{array}{l}0.98 \\
0.92\end{array}$ & $0.50 \pm 2.5 \% *$ & $0.53 \pm 3.5 \% * \star$ \\
\hline $\begin{array}{l}11 \mathrm{MeV} \equiv 1 \text { ectrons } \\
\text { S.S.D. }-100 \mathrm{~cm} \text { to } \\
\text { top of PS } \\
\text { F.S. }-13 \times 10 \mathrm{~cm}\end{array}$ & $0.5 \mathrm{~cm}$ & $204.2 \pm 1.3 \% *$ & $212.5 \pm 2.5 \% * \star$ & 0.96 & - - & - \\
\hline
\end{tabular}

*Te error is the precision in terms of 16 for $N=5$

**Te error in terms of estimated accuracy. The precision is better than $\pm 1 \%$. 


\section{Features of Calorimeter}

Fig. 3

Al case for

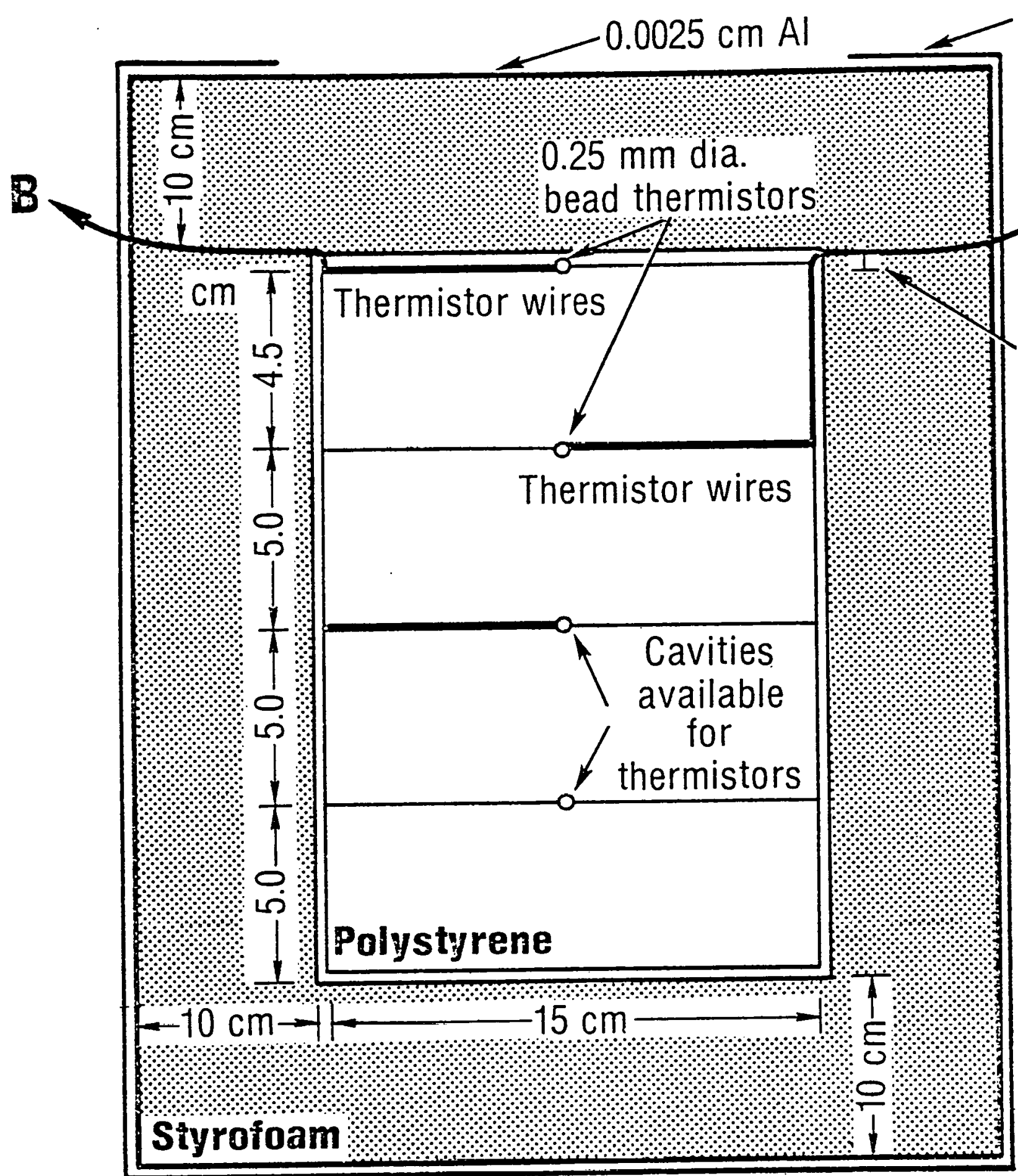

electrical shielding

$0.5 \mathrm{~cm}$

$\mathbf{A} \& \mathbf{B}$ are thermistor

leads each to a

separate Wheatstone

bridge, associated

electrometer and

pen recorder. 


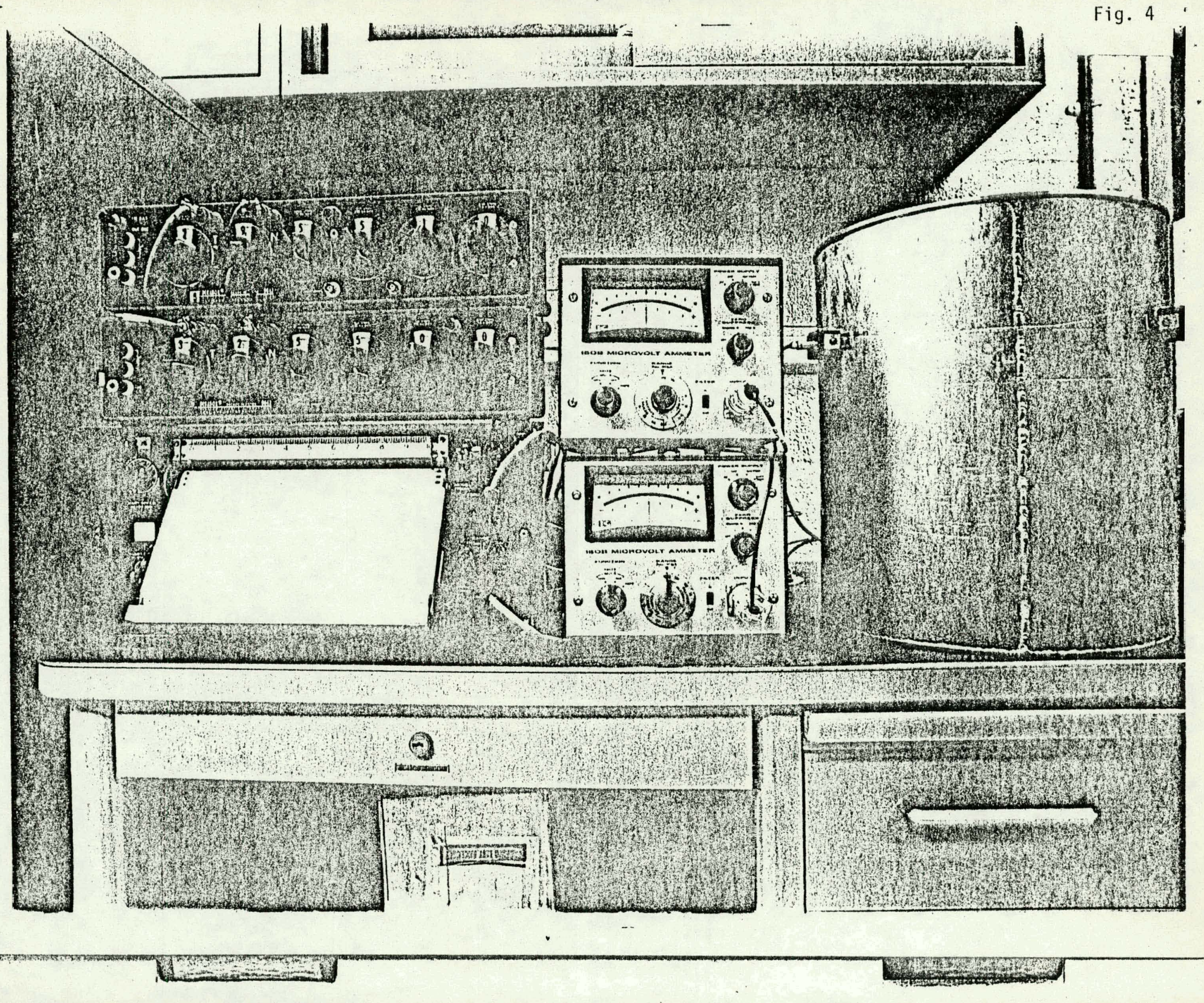




\section{Measurement in Co-60 Field \\ with Thermistors at $5.0 \mathrm{~cm}$ and $0.5 \mathrm{~cm}$} S.A.D. $80 \mathrm{~cm}$ to $0.5 \mathrm{~cm}$ Depth and $8 \times 8$ Field
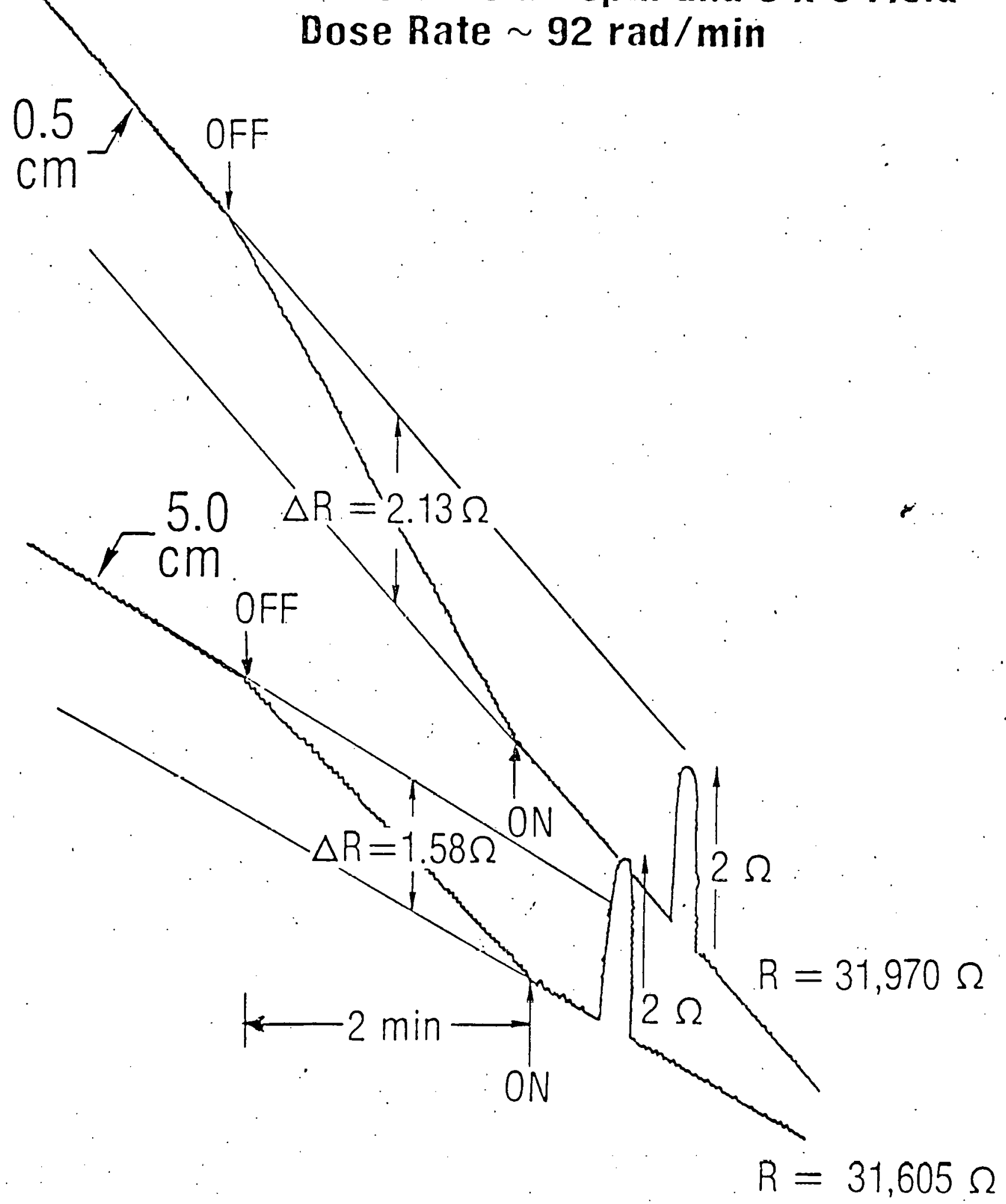

$\longleftarrow$ Time 


\section{Absorbed DOSe in Rad:}

Fig. 6

$D=10^{5}\left(C_{p} / \alpha\right)(\Delta R / R)$, where $C_{p}$ is specific heat of polystyrene (PS) at temp. T, $\alpha$ is thermal coefficient of resistance at $T$ for the thermistor, and $(\Delta R / R)$ is the fractional change of resistance due to increased temperature caused by energy from absorbed radiation. $\alpha=-B / T^{2}$ in the vicinity of room temperature.

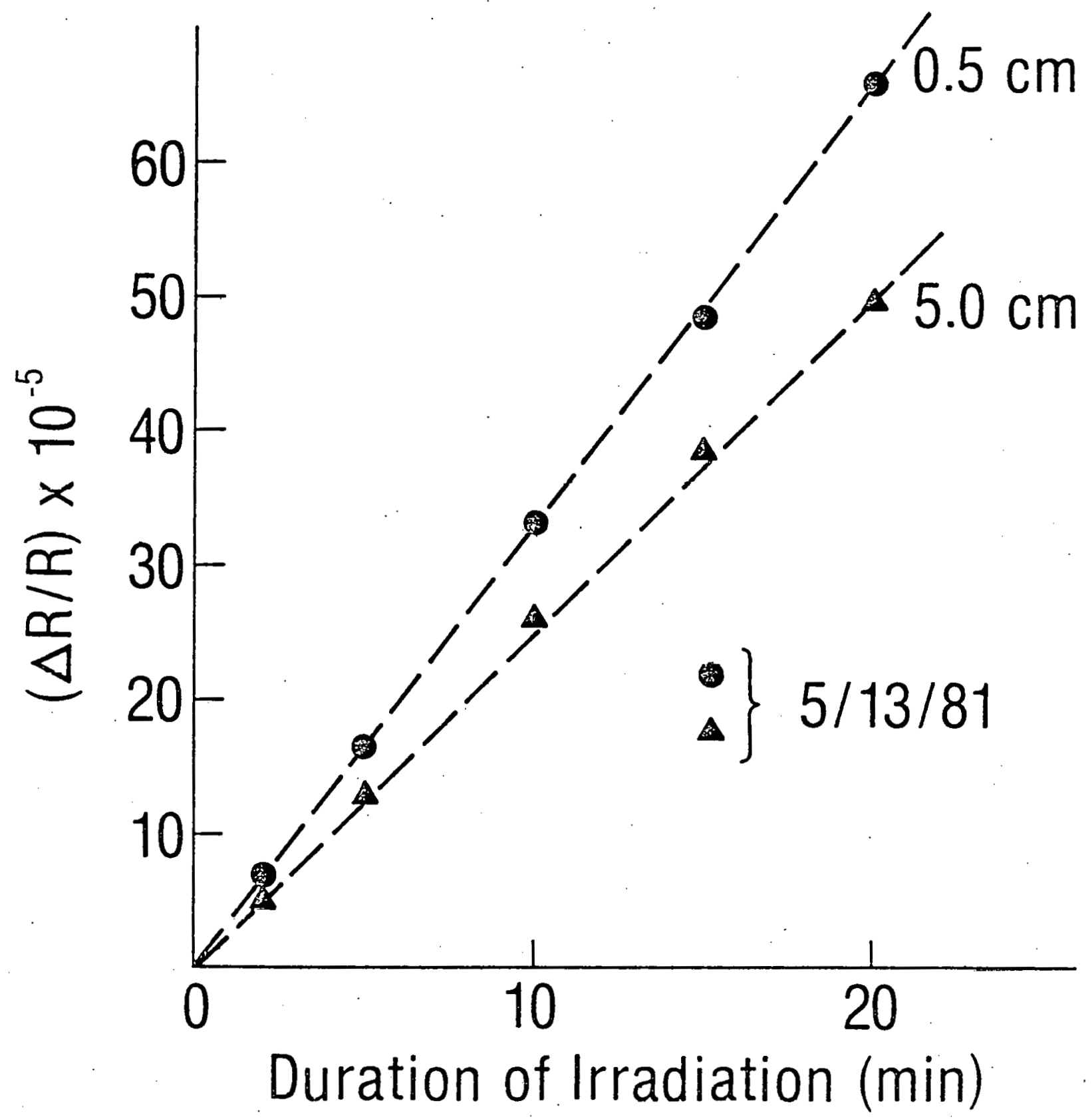


Fig. 7

Absorbed Dose in Arbitrary Units

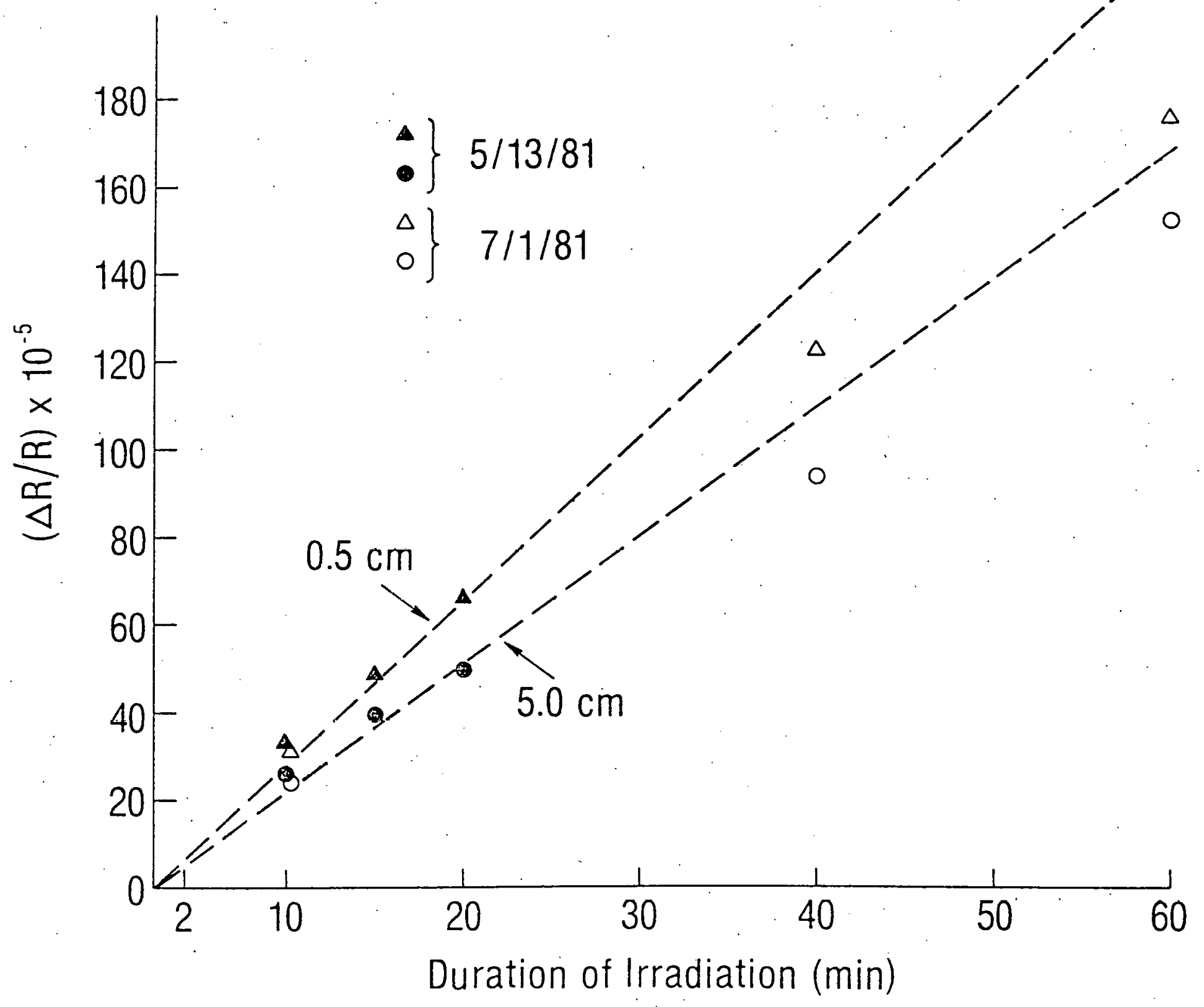




\section{REFERENCES}

1. R.S. Caswell and J.J. Coyne. Sixth Symp. Microd., Brussels, May 22-26, 1978 .

2. R.S. Caswell and J.J. Coyne, Fifth Symp. Microd., Verbania - Pallanza, Italy, September 2-26, 1975.

3. R.S. Caswell and J.J. Coyne, Fourth Symp. Microd., Verbania - Pallanza, Ita1y, September 24-28, 1973.

4. J. Rappaport et a1., Nuclear Physics, 313: 1, 1979.

5. J.C. McDonald and I. Ma., Nuclear Instru. and Methods, 148, 61 (1978).

6. T.R. Canada et a1., Radiat. Res. 60, 205, 1974.

7. J.S. Laughi in, L. Zeitz, J. Liang, and I. Ma., Med. Physics, 8 , 560, 1981.

8. M. Sabel, Th. Schmidt, and H. Pauly, Health Physics, 25, 519, 1973.

9. R.E. Taylor and H. Groot, Specific heat of polystyrene, Properties Research Lab. Report PRL 549, West Lafayette, Ind., Apri1 1981. 


\section{PUBLICATIONS AND PRESENTATIONS}

\section{Publications}

1. Concerning the Event Size Distribution, J.C. McDonald, R.W. Finlay, P. Grabmayr, and G. Randess-Pehrson, Med. Phys. Z, 729, 1980.

2. Unwanted Neutron Contribution to megavoltage $X$-Ray and Electron Therapy, J.S. Laughlin, A Reid, L. Zeitz, and J. Ding. NBS SP 554, $1,1979$.

3. Concerning the Risk in Radiation Therapy due to Unwanted Neutrons, L. Zeitz, Med. Phys. 8, 400, 1981.

4. Advance in Absorbed Dose measurement calculation and application with electrons, J.S. Laughl in, A. Reid, and R. Mohan, Electron Dosimetry and AMC Therapy Symposium, Madison, Wisc., Sept 10-11, 1981. (In Press).

5. Depth Dose-Ratios Determined with a Solid Calorimeter, J.S. Laughlin, L. Zeitz, J. Liang, and I. Ma. Med. Phys. 8, 560, 1981.

6. Phosphorous Neutron Dosimetry for an 18-MV Linear Accelerator, J.R. Bading, L. Zeitz, and J.S. Laught in, Med. Phys. 8, 587, 1981.

7. Microdosimetric measurements of 20 and $25 \mathrm{MeV}$ Neutrons, G. RandersPehrșon, R.W. Finlay, J.C. McDonald, J.F. Dicells, and J. Liang, Radiat. Res. 87, 491, 1981.

\section{Manuscripts}

1. Non-Isolated-Sensor solid polystyrene Absorbed Dose Measurements, L. Zeitz, J.S. Laughlin, J. Liang and I. Ma (Manuscript in preparation).

2. Phosphorus Activation Neutron Dosimetry Applied to an 18-MV Radiotherapy Accelerator, J.R. Bading, L. Zeitz, and J.S. Laughlin (Manuscript in prepartion).

\section{Presentations}

J.S. Laught in

Invited paper, Advance in Absorbed Dose Measurement Calculation and Application with Electrons, at Electron Dosimetry Symposium, Madison, Wisc., Sept 10-11, 1981. 